\title{
A Study on Institution of Corporate Social Responsibility: A Review, Summary and Prospect
}

\author{
Zicheng Liu, Zhiqiang Huang \\ School of Business Administration, South China University of Technology, Guangzhou, China \\ Email:1272003716@qq.com,1561727494@qq.com
}

How to cite this paper: Liu, Z.C. and Huang, Z.Q. (2017) A Study on Institution of Corporate Social Responsibility: A Review, Summary and Prospect. American Journal of Industrial and Business Management, 7, 93-108.

https://doi.org/10.4236/ajibm.2017.72008

Received: January 16, 2017

Accepted: February 18, 2017

Published: February 21, 2017

Copyright $\odot 2017$ by authors and Scientific Research Publishing Inc. This work is licensed under the Creative Commons Attribution International License (CC BY 4.0).

http://creativecommons.org/licenses/by/4.0/

(c) (i) Open Access

\begin{abstract}
A consensus on whether companies should fulfill their social responsibility has been reached in the 1990s. That is: companies should take social responsibility. However, there is no universal acknowledgment about what kind of responsibility companies should take and how to fulfill social responsibility. In this paper, a systematic summary has been built from both the national level and corporate level by reviewing domestic studies on the institution of corporate social responsibility (CSR) in recent years. The study summarizes the defects, the countermeasures, and suggestions of CSR institution on a national level in our country. In addition to the suggestions proposed through comparing Chinese and foreign institutions, this paper mainly summarizes those proposed by domestic scholars that are suitable for China's national conditions. On a corporate level, we summarize the internal management of CSR institution, its external influence on the company, and the functional mechanism of CSR institution for stimulating enterprises to perform social responsibility. We find that the studies of CSR institution on a corporate level mainly focus on the relationship between CSR institution and corporate reputation, competitiveness, and performance. But the conclusion is not absolutely consistent. Most of the researches are normative researches while empirical researches are rare. This study also makes a statistical analysis on 231 articles on CSR institution published in CSSCI by domestic scholars. The analysis shows that the number of related studies reached the breaking point in 2008 and arrived at the peak in 2009, since when it has become a research hotspot. On the variation of research topics, topics change with the development of the society and the transition of social problems. Lastly, based on previous researches, this paper analyzes the prospect of future research content and research directions.
\end{abstract}

\section{Keywords}

CSR Institution, Review, Statistical Analysis, Prospect 


\section{Introduction}

"Corporate Social Responsibility" was first proposed by a western scholar Sheldon in 1924, since when the definition and connotation of CSR had been debated heatedly and even today there is no agreement [1]. There are two core arguments: one is whether companies should bear their social responsibility. This debate lasts until the 1990s and a consensus has been reached, that is, companies should take social responsibility [2]. The other argument is what kind of social responsibility they should bear, which is an important research point both in the academic and practical world. As this dispute encompasses not only theoretical studies on economy, law and ethics, but also practical explorations on relevant institutions, therefore, even today there is no settled answer.

At present, there are scholars in the fields of management, economics, law, sociology, ethics, etc., studying CSR institution in academia, but scholars in the field of law and management are engaged in more specific and in-depth discussions. As the field is different, the angle of view is not the same. Scholars in the field of law, sociology, and economics focus on the problems and suggestions of the existing CSR institution from national macro-perspective, while scholars in the field of ethics and management, from a micro-perspective, tend to explore the enterprises' internal management of social responsibility system, the external impact of social responsibility system on enterprises and the functional mechanism of the system promoting corporate social responsibility. Therefore, this article will review and summarize previous researches from the national and corporate perspective. At the same time, it will analyze the number and topics of relevant researches in the past 16 years through statistical analysis, and put forward some suggestions for future research content and direction.

\section{Research Causes of CSR Institution in China}

The research causes of CSR institution in western countries are social and environmental problems caused by a lack of corporate social responsibility. However, the research causes of CSR institution in our country are relatively diverse and complicated.

\subsection{On National Level}

Scholars who explore China's CSR institution on the national level are mainly in the field of law and sociology, although they are from different perspectives, the research causes of CSR institution are nothing more than the following points.

\section{(1) Barriers to CSR standard}

China became part of the world trading system after its accession to the WTO, and China's enterprises have entered the global supply chain system. In the globalized economy, trade relations between developed and developing countries have deepened. In recent years, due to the appeals of NGOs and the pressure of public opinion, western developed countries have begun to formulate CSR standards such as labor and environmental protection and thus form trade barriers [3], fulfilling their corporate social responsibility and at the meantime set trade 
restrictions to foreign enterprises which lack social responsibility institution. In 2012, South Korea's Samsung group set regulations for Chinese suppliers on corporate social responsibility, which is a typical case. This has made it necessary for China to formulate corresponding CSR institution suitable for China's national conditions and in line with international standards of corporate social responsibility system.

(2) The international standard may not absolutely suit China's national conditions

It is indisputable that western developed countries are doing better in performing corporate social responsibility [4]. As they have not only established comparatively perfect standards of corporate social responsibility system but also have specialized third-party organizations to evaluate on qualified CSR reports. However, due to the gap between China and the developed countries in national conditions and legal construction, the institutionalized practice of corporate social responsibility in western developed countries cannot be simply copied to China [5]. In addition, factors such as national historical and cultural traditions, social norms, and business development stage should be taken into account before a new system is introduced into our country. The development of CSR in European and American countries have entered the stage of internal rules dominant while China is still in the phase of external rules dominant [6]. Hence, there is a great gap between developed and developing countries in terms of national conditions.

\subsection{On Corporate Level}

Scholars who explore the causes of on enterprise level are mainly in the fields of management and ethics. Scholars who explore the cause of CSR institution on national level are slightly different from those on national level. In addition to doing passive research, there is a positive correlation between corporate social responsibility and business performance [7]. Therefore, researches on CSR institution on enterprise level also have a positive effect. Specific causes can be divided into the following two aspects.

(1) Passive research: due to the defective existing CSR institution in China

Since the founding of PRC, the Chinese enterprises have made great progress. However, our understanding of corporate social responsibility is still not clear. During the period of planned economy, the enterprises mistakenly ran social services which were not their obligation, and this increased the burden of corporate development. In the period of the market economy, the enterprises should have taken social responsibility, but they pursued the economic value excessively, which resulted in a loss of social responsibility [8]. Both circumstances manifest an unclear and defective CSR institution in China. Huang Qunhui et al. made a research on evaluation of the development of social responsibility of China's top 100 enterprises in 2009. The result of the study also illustrates this point: the overall level of social responsibility performance of China's top 100 
enterprises is low, of which $20 \%$ have just started, $40 \%$ of the enterprises are still onlookers [9]. Such kind of negative acts reflects that CSR is not well understood by enterprises. Therefore, it is urgent for China to establish a clear CSR institution so that enterprises have rules to follow.

(2) Active exploration: performing CSR is conducive to enterprise development.

In recent years, scholars in the field of management have studied more on CSR not only because enterprises should fulfill CSR, but also because fulfilling CSR is conducive to the long-term development of enterprises. Some scholars have shown that the fulfillment of corporate social responsibility can not only make enterprises get a good reputation [10], contributing to the competitiveness of enterprises, enterprise growth and corporate performance improvement [11], but also help enterprises to establish political business relations to enjoy preferential terms in relevant policies, debt financing, and other scarce resources. Especially in current China, the government has the right to allocate the resources needed for enterprise development, so a good government-business relationship can help promote the rapid development of enterprises [12].

\section{Domestic Research Status of CSR Institution}

In the 1990s, China began to introduce and define the concept of CSR. In 2004, the Fourth Plenary Session of the Sixteenth Central Committee of the Communist Party of China put forward the idea of building a harmonious society. The connotation of corporate social responsibility coincides with the requirements of a harmonious society, which promotes academic research on corporate social responsibility institutionalization and legislation. In 2006, China's new "Company Law" made formal regulations: enterprises should bear social responsibility. This was followed by national policies, local laws and regulations and industry norms concerning CSR. Scholars have extensively discussed on how to promote CSR mechanism based on institutionalization, and have achieved certain results. However, due to the relatively short time, many issues have yet to be further discussed.

\subsection{Research Status of CSR Institution on National Level}

Researches on CSR institution on national level mainly revolves around the problems of the existing system and countermeasures. This paper summarizes the current status of the study based on previous literature review.

\subsubsection{The Defects of Existing CSR Institution}

According to existing researches, the problems existing in CSR institution of our country can be divided into the following four aspects: (1) the existing institution itself is flawed. There is no independent or complete system and it lacks coordination of various laws [13]; (2) the regulations are too principled, so the operability is not strong. e.g., the fifth provision in "Company Law" regulates that companies should bear social responsibility but does clarify how to bear 
responsibility and to which stakeholders do the companies bear responsibility. (3) There is no perfect information disclosure and auditing system. The information on CSR will be selectively disclosed by companies [14]. Although in recent years, some scholars have proposed that large data will make the company's "words" closer to their "actions" [15]; it was only confined to theoretical discussion. In addition, the quality of CSR reports of disclosed companies is not high, without a complete set of evaluation criteria [16]; (4) there is a lack of appropriate incentive-penalty, supervision mechanism [17]. It is necessary to explain that since 2008, studies on defects of CSR institution have been the focus of legal researches. The research topics have basically centered on the above four issues since 2009, in addition to 2008 in which the topic focused on information disclosure system. Although the legislative aspects have been improved, but the institution is still not perfect.

\subsubsection{Suggestions for Perfecting the System}

Most of the recommendations are raised specifically based on the above-mentioned four problems. In addition, scholars have put forward some localized suggestions which should be taken into consideration when formulating relevant policies and regulations: (1) China's cultural traditions, social norms and stages of enterprise development are different from those of western countries, so the standards of CSR institution should link the international standards but at the same time keep Chinese characteristics [18]. (2) There is certain development gap between domestic enterprises which are of different nature and different industries. So when formulating relevant policies and regulations, factors such as the nature and scale of the enterprise, the belonging industry, the development stage and so on should also be taken into account [19]. Most scholars often ignore the importance of this in the process of formulating relevant laws and regulations; (3) Considering the overall development of Chinese enterprises, incentive measures should be dominant and compulsory measures are subsidiary [20], meanwhile, preferential policies are offered to enterprises that actively fulfill their social responsibilities [21]. These localization proposals are consistent with the ideas of "localization management" and "localization study" which is advocated in recent years, and all of them are the "transformation" of the western systems in view of China's specific application scenario. In fact, the formulation of relevant policies and regulations are really tailor-made based on China's specific national conditions.

\subsection{Research Status of CSR Institution on Corporate Level}

There are three types of researches on CSR institution on corporate level. The first type is the corporate internal management of social responsibility. As the internal social responsibility institution is developed by the enterprise itself, and it is not the mandatory requirement of legal system, so such type of researches mainly concentrate on ethics and charity. The second type of research focuses on the external influence of CSR institution on enterprises, featuring the relation- 
ship between the ethnic charitable system and corporate reputation, competitiveness and corporate performance; the third type is the functional mechanism of CSR institution to promote enterprises to fulfill their social responsibilities. Due to the short time, the related researches are not complete.

\subsubsection{The Internal Management of Social Responsibility Institution}

The corporate internal management of social responsibility institution mainly revolves around the definition, connotation, and construction of ethics and charity system. There is no unanimous authoritative argument about the ethical system in the academic circle. An ethical system is often associated with corporate culture. As is generally believed that the ethical system is part of the corporate culture, and it is core and foundation of building corporate culture [22]. Corporate ethical system judges whether employee's behavior is in line with the corresponding organizational norms by principles of justice or injustice, good or evil, setting restrictions on the employees. Unlike corporate rules and regulations, it is a soft constraint, not a mandatory one, but it is unified with the rules and regulations because most of the ethical systems are permeated in the corporate rules and regulations [23]. The construction of the ethical system is usually for employees, consumers, so there is a lack of discussion about suppliers, the environment, community, and government. For a charitable system, there is no clear definition of charity. Charity is a spontaneous behavior, which in most cases is based on the spur of the moment for public welfare or social expectations. Very few companies would develop a standardized charitable donations system. Listed companies and other joint-stock companies in general set certain institutional procedures in terms of charitable donations, which need to go through the discussion of shareholders or senior leadership, but small and medium enterprises such as private enterprises are relatively random, and in most cases, it is based on their self-development.

\subsubsection{The External Influence of CSR Institution on Enterprises}

So far, there haven't been many studies on the external influences, as most scholars tend to explore the impact of corporate social responsibility behavior on enterprises. As is generally believed that behavior is based on the impact of the system (the new institutionalist school), which has reached a consensus on the national level. However, there is clear divergence on the corporate level, because the corporate social responsibility institution is developed by the enterprise itself, so it is a soft constraint and there is no coercion, but enterprise-level corporate social responsibility system is not uniform with corporate social responsibility behavior in reality. At present, few scholars have put forward this phenomenon, some foreign scholars have pointed out that the system is only a ritual of false modification, and there is no association with the actual behavior of corporate social responsibility. Even with a corresponding CSR institution, it is still hard to determine whether the enterprise would perform his social responsibility behavior or not [24]. Therefore, the internal CSR institution and the behavior of the enterprise are relatively independent. This paper argues that although there 
may be inconsistencies between the system and behavior on corporate level, there is no doubt that corporate leaders will not tell others that they do not have to follow the relevant social responsibility institution. Most enterprises' institutions are consistent with their behavior; otherwise, the enterprise will be difficult to develop. Therefore, this paper will review the researches on the social responsibility behavior when summarizing studies on the CSR institution.

(1) The external influence of an ethical system. There are two kinds of research on ethical system: one is normative research, which is the research method adopted by most scholars so far. According to the existing research results, most scholars believe that the ethical system can promote the growth of enterprises and promote the core competitiveness of enterprises [25]. But there is no specific discussion on how ethical system promotes enterprise growth and enhances enterprise competitiveness; the other is empirical research, the amount of which is relatively small. Reachable domestic empirical research is done by is Chao Gang and Shen Chuanquan (2013), who set ethical system as an independent variable and corporate performance as a dependent variable. According to the research results, ethical system does not directly affect the performance of enterprises, but with the aid of the intermediary role of corporate social responsibility behavior [26], that is, the ethical system will not have an impact on enterprise performance until it is implemented through the behavioral practice of corporate social responsibility.

(2) The external influence of the charity system. There are few cases of charity institutionalization in domestic enterprises, and few studies have been done. Most of the researches focus on charitable donation behavior. In the research of charitable act, conclusions are always critical and suspicious rather than positive: One criticism is that the charitable donations are a means for enterprises to obtain political-business relations. Although it is beneficial for individual enterprises, it is detrimental to the development of the whole market. As our economist $\mathrm{Wu}$ Jinglian pointed out that this behavior will cause the governmental rent-seeking behavior and will indirectly hinder market justice [27]; another criticism is that the enterprises do charitable donations in order to cover up or transfer the outside attention for their lack of social responsibility behavior, so it is considered instrumental motivation rather than from the inner heart [28]. Although this criticism is difficult to reach an academic consensus, such cases in real life are indeed everywhere; there is also no definitive conclusions on charitable system researches. Generally, the enterprises' charitable system will bring a good reputation and image to the enterprise, which is beneficial; but such conclusion is not universal. Chinese scholar Zhang Jianjun (2011) made an analysis of China's donation cases; he found that in the event of natural disaster, even if an enterprise made charitable donations if the amount of donation does not meet the public expectations and requirements, it will have an opposite effect. In addition, although the majority of foreign enterprises have established a corresponding donation system to counter natural disasters, the actual effects are not all positive. But in most domestic enterprises, although the charitable donations 
are only a temporary move without a sound system [29], sometimes it will play wonders. A typical case is the Nongfu Spring, which sponsored the activity of buying every bottle of water for donating a penny, which gained a very good reputation.

\subsubsection{The Action Mechanism of CSR Institution to Promote Enterprises to Fulfill Social Responsibility}

At present, the scholars who study the mechanism of action are borrowing the new institutionalist theory in the field of organizational sociology. They regard the enterprise as a perceived object of institutional pressure, and divide the institutional pressure into three modes: regulation, norms and cognition (imitation). Regulation refers to national laws and regulations and industry standards. The main source of pressure comes from the government, professional organizations and industry associations [30]; norms refer to the behavior of enterprises to comply with the corresponding values and ethics. The main source of norms comes form stakeholders, the media, and public expectations; cognition is also known as imitation, which refers to the understanding of the industry to which the enterprise belongs. Cognitive pressure mainly comes from competitive advantages of other companies within the industry [31].

According to the results of the present study, basically all scholars have reached a consensus on the macro conclusion that institution can drive the enterprises to fulfill their social responsibilities through the form of institutional pressure [32] [33]. But in terms of influence degree of regulation, norms and cognition, the scholars' research results are not completely identical, some are even completely opposite. For example, Shen Qi and Tai Song conducted an empirical research and found that the three kinds of pressure: regulation, norms and cognition are significantly exerting a positive impact on corporate social strategy response, driving Chinese enterprises to fulfill their social responsibilities, and among the three pressure, normative and cognitive effects are basically equivalent while the effectiveness of regulatory pressure is relatively weaker than that of the former two [34]. However, the results of Li Bin et al. empirical study showed that the effects of normative pressure is the greatest, cognitive pressure ranks second while regulatory pressure had no significant effect [35]. The results of the two scholars show that the effect of normative pressure is basically the same, the effect of cognitive pressure is significantly different, the effect of regulation pressure is totally different; in addition, Feng Zhen made an empirical study on senior managers who are pressure-sensitive. He found that regulation pressure and normative pressure are the main drivers; cognitive pressures do not necessarily drive corporate social responsibility [36]. So there is a fundamental difference between the results of the first two studies (see Table 1). Such kind of inconsistent and contradictory phenomena shall be further explored in the future.

In addition, it is necessary to mention that the above scholars divide institution into three types based on the theory of neo-institutionalism (regulatory, normative and cognitive) to explore the functional mechanism of how institution 
Table 1. Studies on the impact of institutions on CSR.

\begin{tabular}{|c|c|c|c|}
\hline Researchers & Time & Approach & Results of Empirical Studies \\
\hline $\begin{array}{l}\text { Sheng Qi, } \\
\text { \& Tai Song }\end{array}$ & 2010 & Independent variable: & $\begin{array}{l}\text { The effect of regulation is equal to } \\
\text { cognition. The effect of norms is } \\
\text { weaker than that of the former two. }\end{array}$ \\
\hline Bin Li et al. & 2011 & $\begin{array}{l}\text { new institutionalism } \\
\text { (regulation, norms, cognition) } \\
\text { Dependent variable: }\end{array}$ & $\begin{array}{l}\text { The effect of norms is the greatest, } \\
\text { cognition ranks second, while the effect } \\
\text { of regulation is the not obvious. }\end{array}$ \\
\hline Zhen Feng & 2014 & corporate social responsibility & $\begin{array}{l}\text { There is obvious effect of regulation } \\
\text { and norms while the effect of } \\
\text { cognition is not obvious. }\end{array}$ \\
\hline $\begin{array}{l}\text { Jianjun } \\
\text { Zhang }\end{array}$ & 2011 & $\begin{array}{l}\text { Independent variable: } \\
\text { new/old institutionalism } \\
\text { Dependent variable: charity }\end{array}$ & $\begin{array}{l}\text { The new institutionalism exerts } \\
\text { influence on initial response, and the } \\
\text { old institutionalism exerts influence } \\
\text { on subsequent reaction. }\end{array}$ \\
\hline
\end{tabular}

Data Source: Collected by the authors.

drives enterprises to perform social responsibility. This research method is widely adopted by current academia, but they did not reach a consistent result. Some scholars have explored a new functional mechanism through different research methods. For example, in Zhang Jianjun's study on the factor of donation, he used charitable donation as the research object based on the new and old institutionalism in order to explore the role of the two systems in different stages of donation. The results of the research show that the new institutionalism influences the initial response of foreign enterprises' contributions through internalized value and business practices that new institutionalism highlights, and the old institutionalism influences the follow-up reaction through the social expectation and external pressure that it emphasizes [37]. Hence, he discovered a functional mechanism independent from the above-mentioned results.

In contrast to most studies, there are special reasons for the inconsistency of the study findings. On the one hand, the study of corporate social responsibility institution in China began relatively late, and the research on functional mechanism was only in recent years. On the other hand, the new institutionalism is a theory of the field of organizational sociology, so researches based on new institutionalism can be regarded as interdisciplinary research which is innovative.So it is difficult to be mature in a short period of time.

\subsection{Statistical Analysis of Relevant Domestic Researches on CSR Institution in Last 16 Years}

In this paper, we use the CNKI as the source database, and we search the literature with the key words of corporate social responsibility institution and policies, laws, regulations, measures, methods, ethics and philanthropy as the theme and use fuzzy retrieval in advanced search of journals from 2000 to 2004. A total of 209 academic papers published in CSSCI were collected from the literature on corporate social responsibility institution. We conducted statistical analysis according to the number and theme of these literatures. 


\subsubsection{Quantitative Analysis}

As can be seen from Figure 1, in recent years, the study of corporate social responsibility institution has become a hot topic in academia. Among them, 2008 saw the outbreak of researches on CSR institution, and it arrived at the peak in 2009; to date it has maintained a steady growth since 2010. There are many reasons for the outbreak of researches on CSR institution in 2008: (1) In 2006, the fifth article of the new "Company Law" clearly stipulates that enterprises should bear social responsibility, and then national policies, local laws and regulations, industrial norms concerning CSR appeared. This not only aroused the attention of the academia, but also created a breeding period for 2008 outbreak. (2) Wenchuan earthquake took place in May $12^{\text {th }}, 2008$. In addition to government bailout, an enterprise also needs to assume social responsibility as both the ordinary people and academics think that the development of enterprises is inseparable from the support of society. Therefore, China should also establish a corresponding institution as soon as possible to restrain corporate behavior. (3) The "San LuMilk Powder" incident in September 2008 pushed the expectation of the public to for corporate social responsibility to the peak. They hoped to formulate and perfect the laws and regulations concerning corporate social responsibility as soon as possible. Domestic scholars conducted a series of researches concerning CSR from multiple perspectives, which also indirectly led to the peak in 2009. Since 2010, despite that the situation of CSR fulfillment has been improved, it is still unsatisfactory. How to make enterprises commit to social responsibility more actively is still a hot academic focus. In addition, China has advocated building a harmonious society and governing the country by law in recent years, and the Ministry of Education has provided much scientific research funding, which greatly promoted CSR institution researches.

\subsubsection{Thematic Analysis}

In the same way as above, the theme of the collected 209 literature is classified into four categories: deficiencies and countermeasures on the national level, the internal management of enterprises, the external influence and the functional mechanism. The statistical results are shown in the following figure.

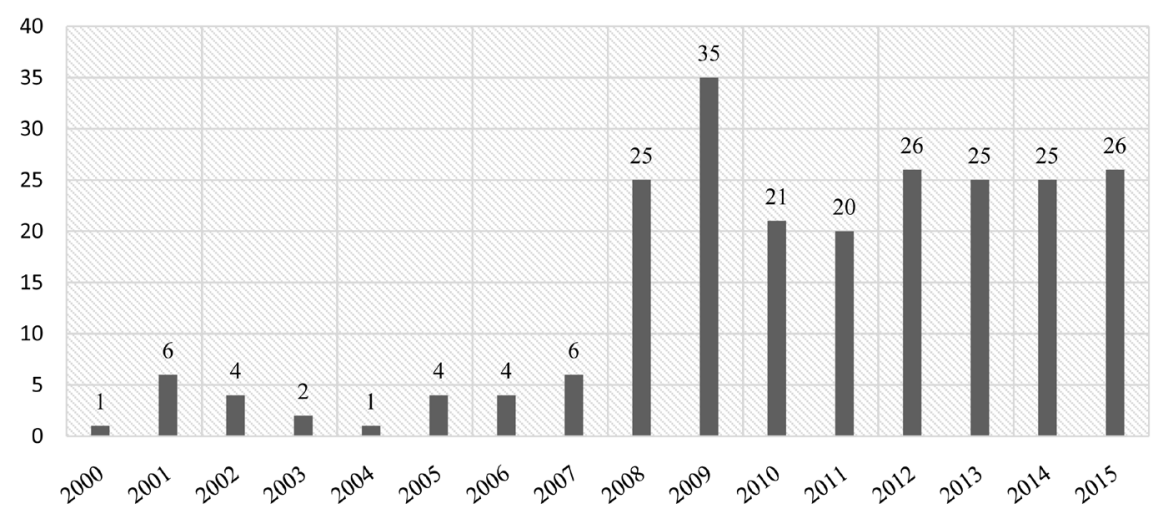

Figure 1. The change of the number of researches on CSR institution in recent 16 years. Data Source: Collected by the authors. 
As can be seen from Figure 2, researches about deficiencies and countermeasures of the existing institution account for more than $50 \%$, which is the focus of academic research in recent years, but it also reflects China's urgent need to establish a sound CSR institution to restrain and guide the behavior of enterprises to promote their fulfillment of corporate social responsibility. The sum of the number of researches on internal corporate management and external influence account for $35 \%$. This shows that a considerable number of scholars, from ethical and charitable perspective, attempted to explore whether fulfilling corporate social responsibility is beneficial for enterprise development, expecting that enterprises can take the initiative to take social responsibility. Only $10 \%$ of the researches concentrate on the functional mechanism, indicating that so far most of the researches are normative and empirical researches are rare.

However, as can be seen from Figure 3, that this ratio is not fixed, the themes of studies change with the development of society and the change of social problems. After 2009, a number of CSR legislations have been introduced and the institution gradually improved. There are legal protections to guarantee corporate social responsibility. More and more scholars have begun to study whether corporate social responsibility is beneficial to the development of the enterprise itself, although there is no agreement; most scholars believe that corporate social responsibility will bring more goodness to the enterprise than harm. In addition, it can be seen from Figure 3 that some scholars have begun to conduct empirical

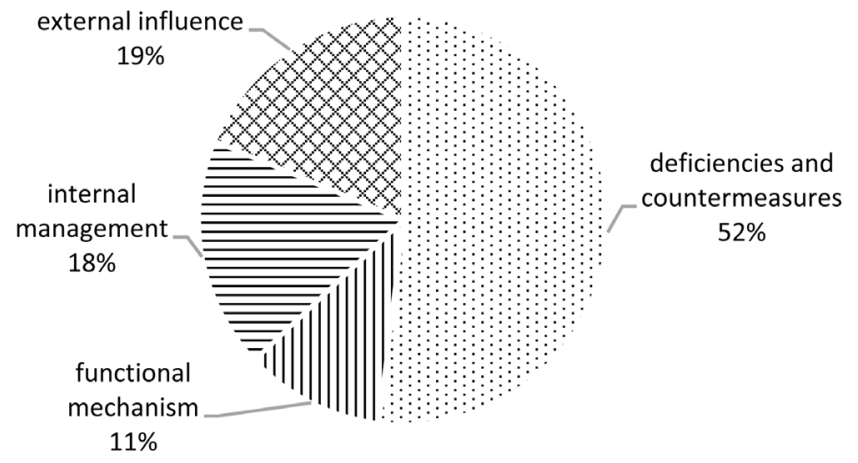

Figure 2. Thematic proportions of researches on CSR institution in recent 16 years. Data Source: Collected by the authors.

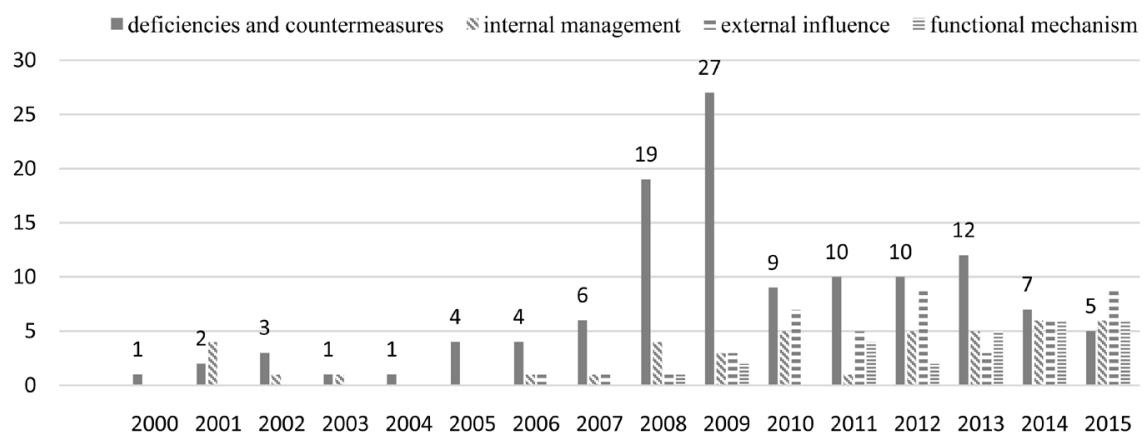

Figure 3. Thematic changes of researches on CSR institution in recent 16 years. Data Source: Collected by the authors. 
studies of how CSR institution promotes enterprises to fulfill corporate social responsibility. Due to relatively short time, there is no uniform result, so it needs to be further explored.

Generally, this section involves the research status of CSR institution in China. Moreover, based on the literature review, this study summarizes the the defects, the countermeasures, and suggestions of CSR institution on a national level in china. Meanwhile, this section also shows a detailed description of the internal management of CSR institution, its external influence on the company, and the functional mechanism of CSR institution. We discover that most of the studies of CSR institution on corporate level tend to concentrate on the relationship between CSR institution and corporate reputation, competitiveness, and performance. This section also shows that most of the researchs are normative researchs and there is a lack of empirical studies. The statistical analysis of 231 articles on CSR institution published in CSSCI by domestic scholars shows that the number of related studies reaches the breaking point in 2008 and arrives at the peak in 2009, since when it has become a research hot spot. As to the variation of the research topics, topics usually change with the development of the society and the transition of social problems.

\section{Summary}

Since the "Harvard controversy" in 1930s, corporate social responsibility has gradually entered into people's vision. Currently, a consensus has been reached on whether enterprises should bear social responsibility, but there is no unified understanding of how to assume social responsibility. This paper has mainly summarized and analyzed domestic researches on corporate social responsibility institution through literature review in recent years.

First of all, this paper summarizes the research causes of corporate social responsibility institution. We can see that the causes of domestic corporate social responsibility institution, compared with those of western developed countries, are more diverse and complex. The research causes, in addition to a serious loss of corporate social responsibility, also include international trade barriers, unsuitable international standards for China's national conditions, unclear awareness of corporate social responsibility, and the benefits of CSR for improving corporate performance.

Secondly, according to the research status, this paper summarizes the deficiencies and countermeasures of China's corporate social responsibility institution from the national level. It can be seen that there are still many problems in the legislation of corporate social responsibility institution in China. Scholars give a lot of specific suggestions, although our legislation is advancing, it is still not perfect; in addition, this article sums up the internal management and external influence of China's corporate social responsibility institution and how the functional mechanism promotes corporate social responsibility fulfillment. I think that studies on the ethical system are not deep enough, and are mostly normative researches lacking empirical results. Moreover, although there are 
quite a few studies on charity, they are too focused on behavior, lacking association with the institution; in terms of the external impact, most scholars believe that the ethical system is beneficial to enterprises, but some scholars conduct empirical studies and contend that this benefit occurs on the premise that the ethical system is transformed into actual corporate social responsibility behavior. The impact of the charitable system on the enterprise is difficult to determine, in addition to the factor such as the action of donation, whether the amount of donation is in line with the expectations of the community is also an important influential factor that will have an impact on the enterprise. The existing research conclusions are mostly critical and doubtful rather than positive. In researches on how the institution promotes social responsibility, as the research time is relatively short and the research is still in the exploration stage, so the conclusions are not completely consistent or even contradictory. But the increase of the number of relevant researches in recent years has had a great theoretical value as well as strong practical significance for providing practical guidance in policymaking.

Finally, this paper has made a statistical analysis on domestic researches about CSR institution in last 16 years. As can be seen from Charts 1, 2, 3, that studies on CSR institution in our country are based on China's national conditions. The institutional advancement is in fact the development social awareness of CSR. The existing researches are mainly focused on the deficiencies of institutions or the suggestions and countermeasures, but the research topics will change with the development of society and the change of social problems. Empirical studies on enterprises will gradually increase in the future.

The contributions of this paper are as follows: (1) The study systematically reviews and summarizes the current research situation of corporate social responsibility institution in China both from the national level and the corporate level. In today's world of growing importance of corporate social responsibility, this paper can be considered as a popular scientific article which involves the research causes, development process, and the research status of CSR in China. Furthermore, this paper provides significant insight for future studies such as the action mechanism of CSR institution to promote social responsibility fulfillment. (2) As the CSR institution in China still needs further improvement, so the deficiencies and constructive suggestions proposed in this paper will provide some references for future establishment of CSR institution.

\section{Limitations and Prospects}

\subsection{Limitations of Research}

Of course, this article still has some limitations; the study of corporate social responsibility institution not only involves the field of management, but also is related to law, economics, sociology and other fields. Due to the researcher's cognitive limitations, the summary and analysis of research results in other fields may not be so concrete. In addition, this article only involves the literature published by domestic scholars on domestic periodicals, not including relevant literature 
published by domestic scholars in foreign journals.

\subsection{Prospects}

By reviewing and rethinking the scholars' research on corporate social responsibility institution in China, we can see that there are still many problems that need to be further explored although some research results have been obtained. For example, there are many problems in legislation of CSR institution in our country. Scholars have given a number of suggestions, but they are relatively broad, and the practical operability is not strong; in terms of the impact of ethical system on corporate performance, most scholars are discussing, in a normative manner, the benefits of ethical system for enterprise development. But the specific functional mechanism is not clear and there is a lack of appropriate empirical research. These problems are of important theoretical and practical significance, and are worthy of further study. In addition, there is another research direction that needs to be noticed.

In researches on how institutions can facilitate enterprises to fulfill their social responsibilities, most scholars take the institution (regulation, norms, cognition) as the independent variable, and the corporate social responsibility as the dependent variable. They get inconsistent or even contradictory conclusions, therefore, the specific functional mechanism is worth studying. In addition, Zhang Jianjun used a new research approach: setting the institutional category (new and old institutionalism) as independent variable, part of corporate social responsibility (charitable donations) as the dependent variable. He discovered a new mode of mechanism which was also of great magnificence for future study.

\section{References}

[1] Li, G.P. and Wei, X.X. (2014) The Implication, Measurement and Economic Consequences of Corporate Social Responsibility-Based on the Foreign Study Summary of Corporate Social Responsibility Theory. Accounting Research, 8, 33-40.

[2] Yan, Y.J. (2011) Strategic Corporate Social Responsibility and Its Seven Strategies. China University of Political Science and Law, 3, 6-8.

[3] Huang, W. and Chen, Z. (2015) Foreign Investment, the Pressure of Supply Chain and Corporate Social Responsibility in China. Management World, 2, 91-132.

[4] Drucker, P.F. (1987) Management: Tasks, Responsibilities, Practices. China Social Sciences Press, 4, 4-5.

[5] Yang, L. (2014) The Institutionalization of Corporate Social Responsibility. Chinese Journal of Law, 5, 131-157.

[6] Huang, X.P. (2007) The Corporate Social Responsibility Policy Basing on the Perspective of Evolution Economics-And the Evolution of Corporate Social Responsibility. Economic Review, 4, 129-137.

[7] Yin, K.G., Liu, X.Q. and Chen, H.D. (2014) Study on the Relationship between Corporate Social Responsibility and Financial Performance from the Endogenous Perspective-Evidence from Chinese Listed Companies. China Soft Science, 6, 98-108.

[8] Chen, D.Y., He, X.F. and Tang, H. (2011) The Path of Chinese Corporate Social Responsibility under the Changes of Institutional Environment. China Population, Resources and Environment, 8, 49-54. 
[9] Huang, Q.H. and Peng, H.G. (2009) Evaluating the Level of Responsibility Management and CSR Information Disclosure of Top 100 Companies in China. China Industrial Economies, 10, 23-35.

[10] Xie, P.H. and Zhou, Z.C. (2009) The Effects of Two Kind of Corporate Publicity on the Customer-Brand Relationship. Nankai Business Review, 12, 64-70.

[11] Tian, H. (2009) The Correlation between CSR and Corporate Performance-Cased on Empirical Date in China's Telecommunications Industry. Economic Management, 1, 72-79.

[12] Li, W., Wang, P. and Xu, Y. (2015) Philanthropy, Political Connection and Debt Finance: Re-Ciprocal Behavior of Governments and Private Enterprises. Nankai Business Review, No. 1, 4-14.

[13] Wang, D. (2009) On Government as a Driver of Corporate Social Responsibility. East China University of Political Science and Law, 5, 93-94.

[14] Li, Z. and Xiang, R. (2007) Study on Content Definition, Measure Methods and Status Quo of Information Disclosure on Community Responsibility in Chinese Enterprises. Accounting Research, No. 7, 3-11.

[15] Shen, Y., Xu, G. and Wang, Z. (2014) The CSR Disclosure Reflects the CSR Practice-A Approach Base on the Big Data Era. Accounting Research, No. 9, 29-36.

[16] Luo, J. (2007) The Study about Institution of CSR Information Disclosure. Economic Review, No. 6, 71-73.

[17] Ye, J., Luo, Z. and Lin, Y. (2007) The Status and Strategy of CSR in China. CASS Forum, 12, 79-82.

[18] Shen, S. and Chen, H. (2008) On Economic Globalization \& Construction of Enterprises Social Liability System in China. Chinese Journal of Law, No. 3, 28-31.

[19] Li, B. (2010) The Study of Corporate Social Responsibility and Its Implementation Mechanism. Southwestern University of Finance and Economics, 4, 183.

[20] Xu, L. and Feng, Q. (2014) The "Rules-Activities Corridor" of Private Enterprise Social Responsibility and Policy Choice Mechanism. East China Economic Management, No. 8, 29-33.

[21] Zhang, Q. (2010) A Analysis on System Mechanism for Lack of Corporate Environmental Responsibility. Study in Dialectics of Nature, No. 2, 78-82.

[22] Xu, X. (2012) The Virtue of Institution-The Important Effects of Enterprise Ethics on the Instruction of Enterprise System. Studies in Ethics, No. 3, 84-88.

[23] Wu, W. (2005) Research on Corporate Culture and Development of Private Enterprises. Wuhan University, 4, 27-28.

[24] Meyer, J. and Rowan, B. (1977) Institutionalized Organization: Formal Structure as Myth and Ceremony. American Journal of Sociology, 83, 340-363. https://doi.org/10.1086/226550

[25] Zhou, Z. (2002) Moral Excellence Based Competitive Advantage. Nankai Business Review, No. 2, 59-66.

[26] Chao, G. and Shen, C. (2013) Empirical Study on Relationship among Ethical Institution, Corporate Social Responsibility Behavior and Organizational Performance. China Population, Resources and Environment, No. 9, 143-148.

[27] Wu, J. (2013) The Shadow of China. Jiangsu Publishing House of Literature and Art, 5, 52-54.

[28] Gao, Y., Chen, Y. and Zhang, Y. (2012) Red Scarf or Green Scarf: The Motivation of Private Enterprises' Charity Behaviors. Management World, No. 8, 106-114.

[29] Zhou, Y. (2006) The Ethical Analysis of Corporate Donation. Hunan Normal Uni- 
versity, 5, 53-72.

[30] Scott, W.R. (2001) Institutions and Organizations. 2nd Edition, Sage, Thousand Oaks, 21-22.

[31] Terlaak, A. (2007) Order without Law? The Role of Certified Management Standards in Shaping Social Designed Firm Behavior. Academy of Management, No. 32, 3.

[32] He, Y., Tang, M. and Wang, S. (2012) On Institution Rationality and Behavior Logic of Corporate Social Responsibility: From the Perspective of Legitimacy. Journal of Business Economics, No. 7, 74-81.

[33] Jia, X. and Liu, Y. (2014) External Environment, Internal Resource and Corporate Social Responsibility. Nankai Business Review, No. 6, 13-18.

[34] Shen, Q.T.S. (2010) A Study on the Institutional Pressures' Influence on the Corporate Social Performance: An Organizational Legitimacy Perspective. Zhejiang University, Hangzhou, 151.

[35] Li, B., Gu, H. and Gao, W. (2011) An Empirical Study on the Effect of Institutional Pressures on Corporate Social Responsibility of Tourism Enterprises. Nankai Business Review, No. 6, 67-75.

[36] Feng, Z. (2014) Conformity or Compliance: Corporations' Choice of Social Responsibility under Institutional Pressure. Finance \& Economics, 4, 82-90.

[37] Zhang, J. (2011) The Driving Factors of Foreign Companies' Donation: A Two-Stage Model of System. Management World, No. 7, 98-112.

\section{Scientific Research Publishing}

\section{Submit or recommend next manuscript to SCIRP and we will provide best} service for you:

Accepting pre-submission inquiries through Email, Facebook, LinkedIn, Twitter, etc. A wide selection of journals (inclusive of 9 subjects, more than 200 journals)

Providing 24-hour high-quality service

User-friendly online submission system

Fair and swift peer-review system

Efficient typesetting and proofreading procedure

Display of the result of downloads and visits, as well as the number of cited articles

Maximum dissemination of your research work

Submit your manuscript at: http://papersubmission.scirp.org/

Or contact ajibm@scirp.org 